\title{
Density Functional Theory Study on the Electronic Structures of Oxadiazole Based Dyes as Photosensitizer for Dye Sensitized Solar Cells
}

\author{
Umer Mehmood, ${ }^{1}$ Ibnelwaleed A. Hussein, ${ }^{1}$ Khalil Harrabi, $^{2}$ and Shakeel Ahmed ${ }^{3}$ \\ ${ }^{1}$ Department of Chemical Engineering, King Fahd University of Petroleum \& Minerals (KFUPM), P.O. Box 5050, \\ Dhahran 31261, Saudi Arabia \\ ${ }^{2}$ Department of Physics, KFUPM, P.O. Box 5050, Dhahran 31261, Saudi Arabia \\ ${ }^{3}$ Center for Refining \& Petrochemicals, KFUPM, Dhahran 31261, Saudi Arabia
}

Correspondence should be addressed to Ibnelwaleed A. Hussein; ihussein@kfupm.edu.sa

Received 10 December 2014; Revised 20 May 2015; Accepted 3 June 2015

Academic Editor: Bart Partoens

Copyright (c) 2015 Umer Mehmood et al. This is an open access article distributed under the Creative Commons Attribution License, which permits unrestricted use, distribution, and reproduction in any medium, provided the original work is properly cited.

The molecular structures and UV-visible absorption spectra of complex photosensitizers comprising oxadiazole isomers as the $\pi$ bridges were analyzed by density functional theory (DFT) and time-dependent DFT. The ground state and excited state oxidation potentials, HOMOs and LUMOs energy levels, and electron injection from the dyes to semiconductor $\mathrm{TiO}_{2}$ have been computed in vacuum here. The results show that all of the dyes may potentially be good photosensitizers in DSSC. To justify the simulation basis, N3 dye was also simulated under the similar conditions. Simulated absorption spectrum, HOMO, LUMO, and band gap values of $\mathrm{N} 3$ were compared with the experimental values. We also computed the electronic structure properties and absorption spectra of dye $/\left(\mathrm{TiO}_{2}\right)_{8}$ systems to elucidate the electron injection efficiency at the interface. This work is expected to give proper orientation for experimental synthesis.

\section{Introduction}

The conversion of photoenergy into electrical energy is generally considered as the most potential way to resolve the world energy crisis, owing to its huge reserves. The inorganic silicon based solar cells are being currently used on a commercial scale because of their high efficiency. However, the need of highly purified silicon, use of toxic chemicals in their manufacture, and the high cost have restricted their worldwide use. These constraints encouraged the search for low cost and environmentally friendly solar cells. In this context, dye sensitized solar cells (DSSCs) have received widespread attention in recent years because of their easy processing and low cost [1-6].

The working principle of the DSSCs is based on light absorption in a photosensitizer anchored on $\mathrm{TiO}_{2}$ semiconductor. Upon absorption of photoenergy, the electrons in the sensitizer become exited from ground state to the excited state. Due to the difference in energy levels of the electronic states, electrons from the excited state are injected to the conduction band of the semiconductor. As a result the dye becomes oxidized. The electrolyte, which is in contact with the dye, then donates electrons to the dye for the regeneration of sensitizer. Electrolyte then diffuses towards the counter electrode where the reduction reaction takes place and electrolyte restores its initial state by accepting electrons at the counter electrode.

The overall efficiency of the DSSCs depends on the photosensitizer. Photosensitizers are categorized into metal complex and metal-free organic sensitizers. But metal-free organic photosensitizers are preferred over ruthenium based sensitizers because of their low cost and good transport properties. The basic structural unit of metal-free dyes is 
donor-pi-spacer-acceptor (D- $\pi-A)$. The photovoltaic properties of such dyes can be finely tuned by selecting suitable groups within the D- $\pi$-A structure [7]. Many organic groups such as porphyrins [8], styrylarylenes [9], perylenes [10], benzofurans [11], indoles [12], and oxadiazole [13] have been used to tune optical properties of photosensitizers. But the oxadiazole derivatives are considered as the most efficient electron transport materials owing to their good thermal and chemical stabilities and high quantum yield [14]. Many studies have been presented in which 2-(4-biphenylyl)-5-(4tertbutylphenyl)-(1,3,4) oxadiazole exhibits excellent charge transport properties $[13,15-18]$. Zhu et al. successfully synthesized the naphthalimide derivatives containing oxadiazole moiety. They found that oxadiazole moiety increases the electron injection properties and minimizes the carrier recombination [15].

DFT/TD-DFT is an effective tool in investigating the ground and excited state properties of photosensitizer complexes as compared to other high level quantum approaches because the computed orbitals are suitable for the typical MO-theoretical analyses and interpretations [19]. Many theoreticians have successfully applied this approach in the designing of photosensitizers [20-25].

\section{Theoretical Background}

The performance of DSSCs is evaluated by incident photon to conversion efficiency (IPCE). It is associated with charge collection efficiency $\left(\eta_{c}\right)$, electron injection efficiency $\left(\phi_{\text {injc }}\right)$, and light harvesting efficiency (LHE), as

$$
\mathrm{IPCE}=\mathrm{LHE} \times \phi_{\text {injc }} \times \eta_{c} .
$$

LHE can be calculated in the following way [26]:

$$
\mathrm{LHE}=1-10^{-f} \text {, }
$$

where " $f$ " is the absorption of dye associated with maximum absorption also called oscillator strength and $\phi_{\text {injc }}$ is directly proportional to the free energy of electron injection as [20]

$$
\phi_{\text {injc }} \alpha f\left(-\Delta G^{\text {inject }}\right) \text {. }
$$

Equation (3) shows that the more positive is $\Delta G^{\text {inject }}$ the greater will be the electron injection efficiency, while $\Delta G^{\text {inject }}$ is the difference between oxidation potential energy of the excited state (Eox ${ }^{\text {dye } *}$ ) and the reduction potential energy of $\mathrm{TiO}_{2}$ conduction band $\left(E_{\mathrm{CB}}\right)$, which can be described as [24]

$$
\Delta G^{\text {inject }}=\text { Eox }^{\text {dye* }}-E_{\mathrm{CB}} .
$$

$\mathrm{TiO}_{2}$ cluster was also simulated and its $E_{\mathrm{CB}}$ was found to be $-4.01 \mathrm{eV}$ (in vacuum). Similarly, Eox ${ }^{\text {dye* }}$ can be calculated by using the following equation [21]:

$$
\text { Eox }^{\text {dye } *}=\text { Eox }^{\text {dye }}-\Delta E \text {, }
$$

where Eoxdye (-HOMO) [22] is the dye's ground state oxidation potential and $\Delta E$ is the lowest absorption energy associated with $\lambda_{\text {max }}$.

\section{Computational Details}

All the DFT/TD-DFT calculations were executed using Amsterdam Density Functional (ADF) program (2013.01) [19]. The ground state geometries of oxadiazole dyes, dye $/\left(\mathrm{TiO}_{2}\right)_{8}$, and standard dyes were optimized by applying hybrid B3LYP level together with triple- $\zeta$ polarization basis function. $\left(\mathrm{TiO}_{2}\right)_{8}$ nanoparticles cluster was also simulated by considering generalized gradient approximation (GAD) at BYLP level and triple- $\zeta$ polarization basis function. UVVis spectra of oxadiazole dyes were simulated in ethanol solvent. Here the conductor-like screening model (COSMO) was selected to take the solvent effects into account [20], while the excitation energies were examined using TD-DFT and statistical average of orbital potentials (SAOP) model including the salvation effects [27]. Seventy singlet-singlet transitions were calculated, which are sufficient to fully define the whole absorption spectrum. In all the calculations, the relativistic effects were taken into account by the zero-order regular approximation (ZORA) Hamiltonian in its scalar approximation [28].

\section{Results and Discussion}

4.1. Designed Systems. The structures and names of new class of dyes are shown in Figure 1. In these structures, biphenyl unit was used as electron-donating moiety and carboxyl and cyano groups $(-\mathrm{COOH}$ and $-\mathrm{CN}$ ) were introduced as the electron acceptor and the anchor groups because of their high ability of electron-withdrawing and bonding to semiconductor. While oxadiazole isomers were introduced as $\pi$-conjugation to bridge the donor-acceptor systems, a double bond and a thiophene unit were also introduced to the pi-conjugation system for the fine tuning of molecular planar configurations and to broaden the absorption spectra. Here the performance of dyes has been tested by introducing different isomers of oxadiazoles as $\pi$-conjugated bridges.

4.2. Energy Levels. The HOMOs, LUMOs, and band gap energies of photosensitizers play an important role in providing the thermodynamic driving force for the electrons injection. For efficient charge transfer, the LUMOs of dyes must be more negative (-LUMOs of dyes must be less negative) than the conduction band of the semiconductor while HOMO levels must be more positive (-HOMO levels must be more negative) than the redox potential of electrolyte. The HOMOs, LUMOs, and LUMO-HOMO energy gap of N3 computed at hybrid B3LYP level are in good agreement with the experimental values as shown in Table 1(a). Thus, hybrid B3LYP function with triple- $\zeta$ polarization basis function can be a valid function for the geometry optimization of oxadiazole based photosensitizers.

Table 1(b) shows the HOMOs, LUMOs, and HOMOLUMO energy gaps of oxadiazole photosensitizers. The HOMO levels of the systems are in the order of system 4 $(-5.919)<$ system $3(-5.865)$ system $1(-5.682)<$ system 2 $(-5.508)$. The LUMO energy levels are in the order of system $4(-3.882)<$ system $1(-3.867)<$ system $3(-3.762)<$ system $2(-3.630)$. It can be seen that the insertion of oxadiazole 


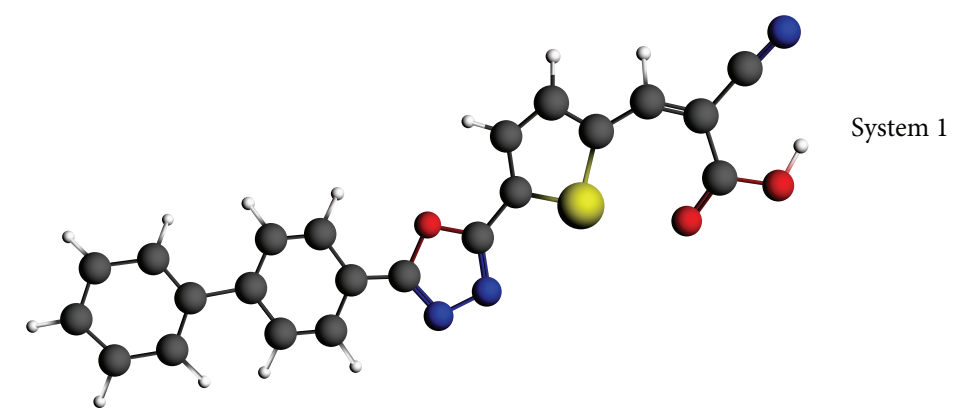

5-(5-([1,1'Biphenyl]-4-yl)-1,3,4-oxadiazol-2-yl)-cyanoacrylic acid

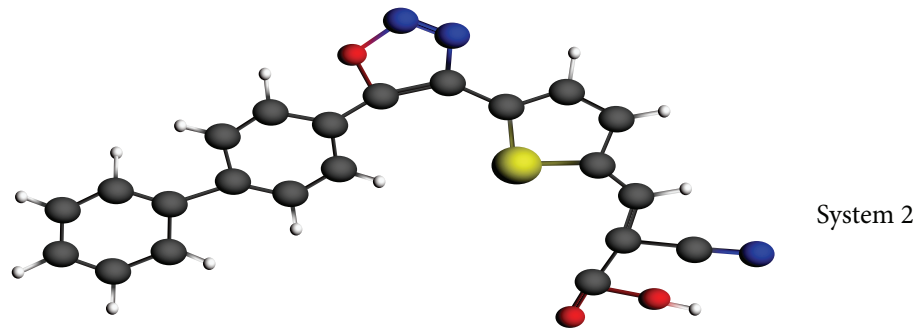

5-(5-([1,1'Biphenyl]-4-yl)-1,2,3-oxadiazol-4-yl)-cyanoacrylic acid

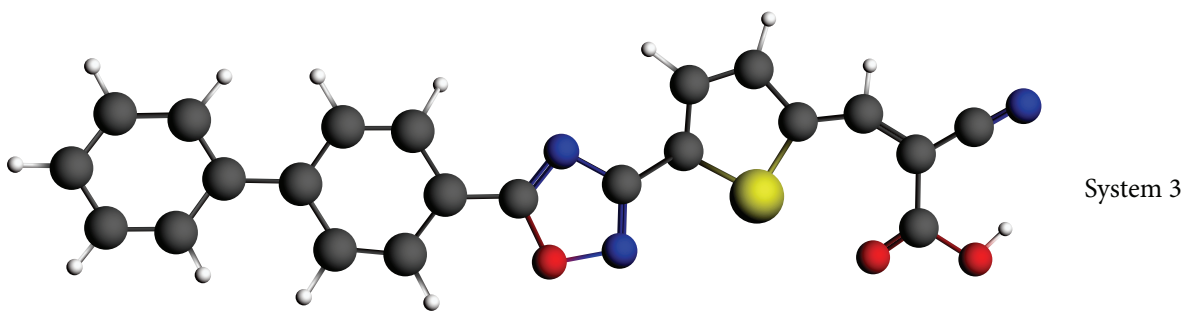

5-(5-([1,1'Biphenyl]-4-yl)-1,2,4-oxadiazol-3-yl)-cyanoacrylic acid

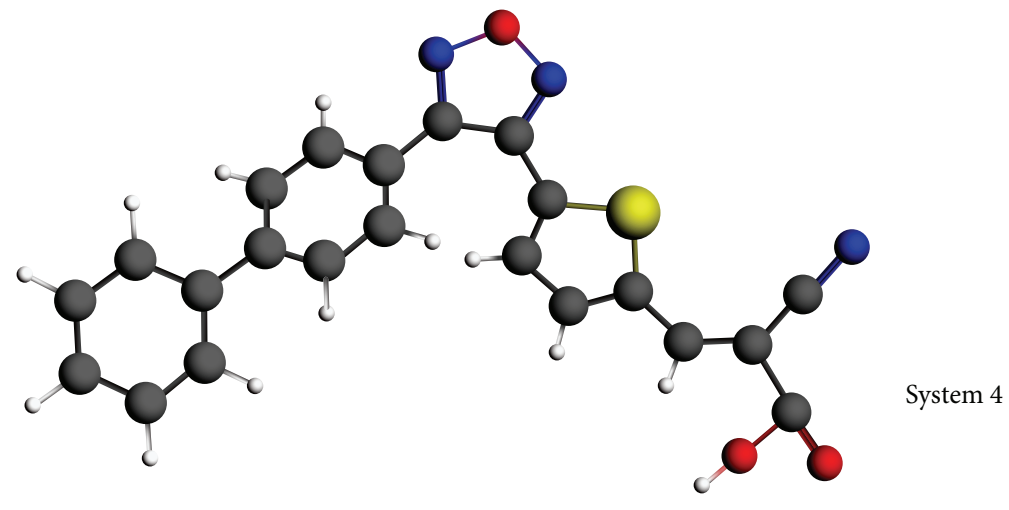

5-(5-([1,1'Biphenyl]-4-yl)-1,2,5-oxadiazol-3-yl)-cyanoacrylic acid

Figure 1: Chemical structures of organic dyes.

isomers as $\pi$-conjugation significantly influences the HOMO and LUMO energy levels. Similarly, the $\mathrm{H}-\mathrm{L}_{\text {gap }}$ of systems are in the order of system $1(1.815)<$ system $2(1.878)<$ system $4(2.037)<$ system $3(2.103)$. These results suggest that systems 1-4 should be capable of injecting electrons into the conduction bands of $\mathrm{TiO}_{2}$.

4.3. Absorption Spectra of Dyes. An efficient photosensitizer should show intense absorption in the visible region
(400 $\mathrm{nm}$ to $700 \mathrm{~nm}$ ). The absorption peaks of simulated N3 sensitizer as shown in Figure 2(a) are closer to the experimental values shown in Table 1(a). Thus COSMO solvation model along with SAOP function can be a valid choice for computing the excited state properties of oxadiazole based photosensitizers.

Similarly, the simulated absorption spectra of systems 1-4 are shown in Figure 2(b). All the absorption spectra of dyes can be clearly divided into two regions with first 
TABLE 1: (a) The FMOs, $\mathrm{H}_{-} \mathrm{L}_{\text {gap }}$ energies, and absorption peaks of N3. (b) The FMO $(\mathrm{eV})$ and $\mathrm{H}-\mathrm{L}_{\text {gap }}(\mathrm{eV})$ energies of systems 1-4.

(a)

\begin{tabular}{lcccc}
\hline Dye & $\begin{array}{c}\text { LUMO } \\
(\mathrm{eV})\end{array}$ & $\begin{array}{c}\mathrm{HOMO} \\
(\mathrm{eV})\end{array}$ & $\begin{array}{c}\mathrm{H}-\mathrm{L}_{\text {gap }} \\
(\mathrm{eV})\end{array}$ & $\begin{array}{c}\text { Wavelength } \\
(\mathrm{nm}) \text { of } \\
\text { absorption } \\
\text { peaks }\end{array}$ \\
\hline $\begin{array}{l}\mathrm{N}^{+} \\
\text {(experimental) }\end{array}$ & -3.47 & -5.36 & 1.89 & $311,385,530$ \\
$\mathrm{~N} 3$ (simulated) & -3.67 & -5.63 & 1.96 & $322,405,542$ \\
\hline
\end{tabular}

${ }^{+}$Experimental [29].

(b)

\begin{tabular}{lccc}
\hline System & LUMOs $(\mathrm{eV})$ & HOMOs $(\mathrm{eV})$ & $\mathrm{H}^{-\mathrm{L}_{\text {gap }}(\mathrm{eV})}$ \\
\hline 1 & -3.867 & -5.682 & 1.815 \\
2 & -3.630 & -5.508 & 1.878 \\
3 & -3.762 & -5.865 & 2.103 \\
4 & -3.882 & -5.919 & 2.037 \\
\hline
\end{tabular}

intense peak in the region of 326-500 $\mathrm{nm}$ and second peak in the region of $472-700 \mathrm{~nm}$. The band in the UV-region is probably emerging from the transitions of electrons localized within the biphenyl unit. The absorption occurring in the visible region is due to transfer of electrons from donor to acceptor, which is sensitive to the nature of the conjugation pathway and red shifts on progressive addition of thiophene units. System 2 with 1,2,3-oxadiazole as pi-bridge exhibits a significant red shift as compared to other systems. It can also be observed that system 2 with 1,2,3-oxadiazole bridge shows a broader peak.

Ground and excited state potential $\left(E_{\mathrm{ox}}{ }^{\text {dye }}\right)$, maximum absorption $\left(\lambda_{\max }\right)$, oscillation strength $(f)$, and main transitions are presented in Table 2 . The main molecular orbitals (MOs) involved in the dominant electron transitions of systems 1-4 are shown in Figure 3. The major transitions may be attributed to the transfer of charge from phenyl group to $-\mathrm{COOH}$ and $-\mathrm{CN}$ through the thiophene unit and $\pi$ conjugation.

4.4. UV-Vis Absorption Spectra of Dyes on $\mathrm{TiO}_{2}$ Surface. The interface between sensitizers and $\mathrm{TiO}_{2}$ plays an important role in the electron injection efficiency. But $\left(\mathrm{TiO}_{2}\right)_{8}$ model was selected because of its balanced electronic properties (conduction band of $\sim-4.0 \mathrm{eV}$ and band gap of $3.18 \mathrm{eV}$ ) $[27,28]$. BAND mode was used to simulate the anatase $\mathrm{TiO}_{2}$ cluster. Here, we selected tetragonal anatase crystal structure with single-layer (001) surface slab. Then, a $4 \times 1$ supercell was created from this slab. All atoms were mapped within the unit cell $[5,27,28]$. The models of dyes linked on $\left(\mathrm{TiO}_{2}\right)_{8}$ are shown in Figure 4, while the simulated UV-Vis spectra of dyes $/\left(\mathrm{TiO}_{2}\right)_{8}$ are shown in Figure 5. The spectra show a dramatic red shift as compared to those in solution. The red shifts values of system 1 , system 2 , system 3 , and system 4 are $20,25,15$, and 19 , respectively. This may be due to the increased delocalization of the $\pi^{*}$ orbital of the conjugated framework caused by the interaction between the carboxylate

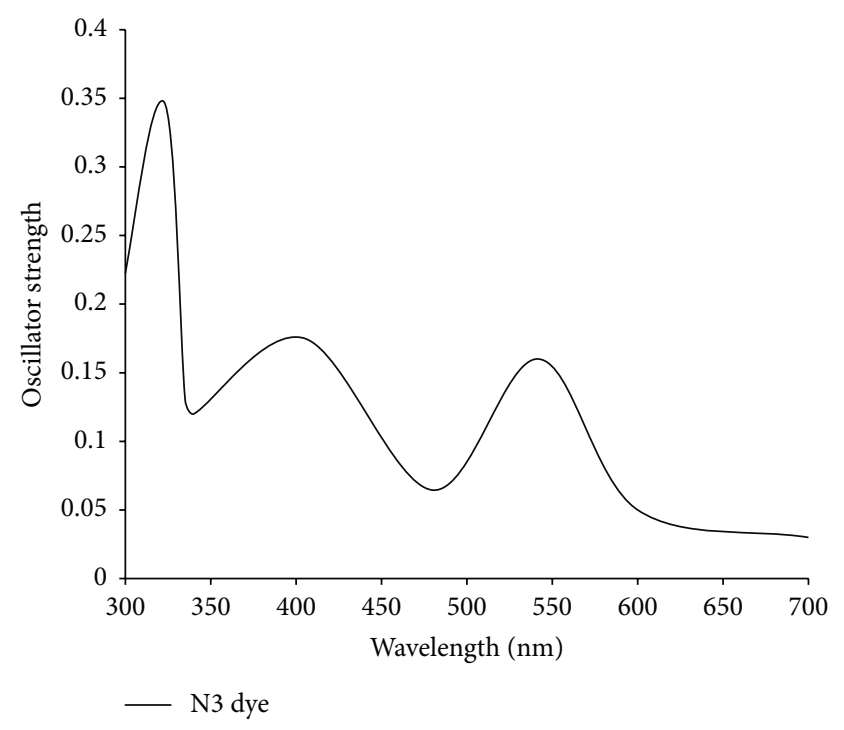

(a)

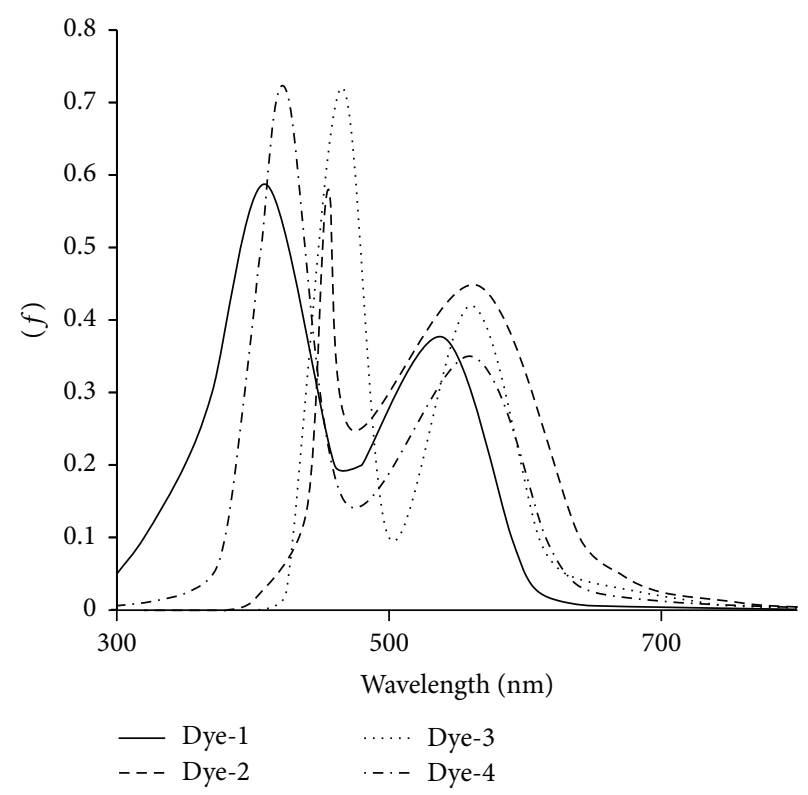

(b)

FIGURE 2: Simulated absorption spectra of (a) N3 and (b) systems $1-4$.

group and the $\mathrm{Ti}^{+4}$ ions that directly decreases the energy of the $\pi^{*}$ level. It can also be observed that dye (3)/ $\mathrm{TiO}_{2}$ show higher red shift value as compared to other systems. The calculated excitation energies, oscillation strength, $\lambda_{\max }$ $(\mathrm{nm})$, and dominant transitions are shown in Table 3.

4.5. Free Energy of Electron Injection and Light Harvesting Efficiency. LHE and $\Delta G^{\text {inject }}$ can be calculated by using (2) and (4), respectively. The results are given in Table 4 . It can be found from Table 4 that all the calculated $\Delta G^{\text {inject }}$ values are positive, which indicates that the conduction band edge of $\mathrm{TiO}_{2}$ lies blow the excited state of the dyes, thus favoring 
TABLE 2: Optical, redox potentials, oscillator strengths, and major transitions of oxadiazole based photosensitizers.

\begin{tabular}{lcccccc}
\hline System & $E_{\text {ox }}^{\text {dye }}(\mathrm{eV})$ & $E_{\text {ox }}^{\text {dye* }}(\mathrm{nm})$ & $\Delta E(\mathrm{~nm})$ & $\lambda_{\max }(\mathrm{nm})$ & $f$ & Main transition \\
\hline 1 & 5.682 & 3.482 & 2.3 & 540 & 5.59 & $\mathrm{H} \rightarrow \mathrm{L}(96 \%)$ \\
2 & 5.508 & 3.308 & 2.2 & 565 & 0.58 & $\mathrm{H} \rightarrow \mathrm{L}(91 \%)$ \\
3 & 5.865 & 3.765 & 2.2 & 561 & 0.72 & $\mathrm{H}-1 \rightarrow \mathrm{L}(86 \%)$ \\
4 & 5.919 & 3.719 & 2.2 & 563 & 0.71 & $\mathrm{H} \rightarrow \mathrm{L}(95 \%)$ \\
\hline
\end{tabular}
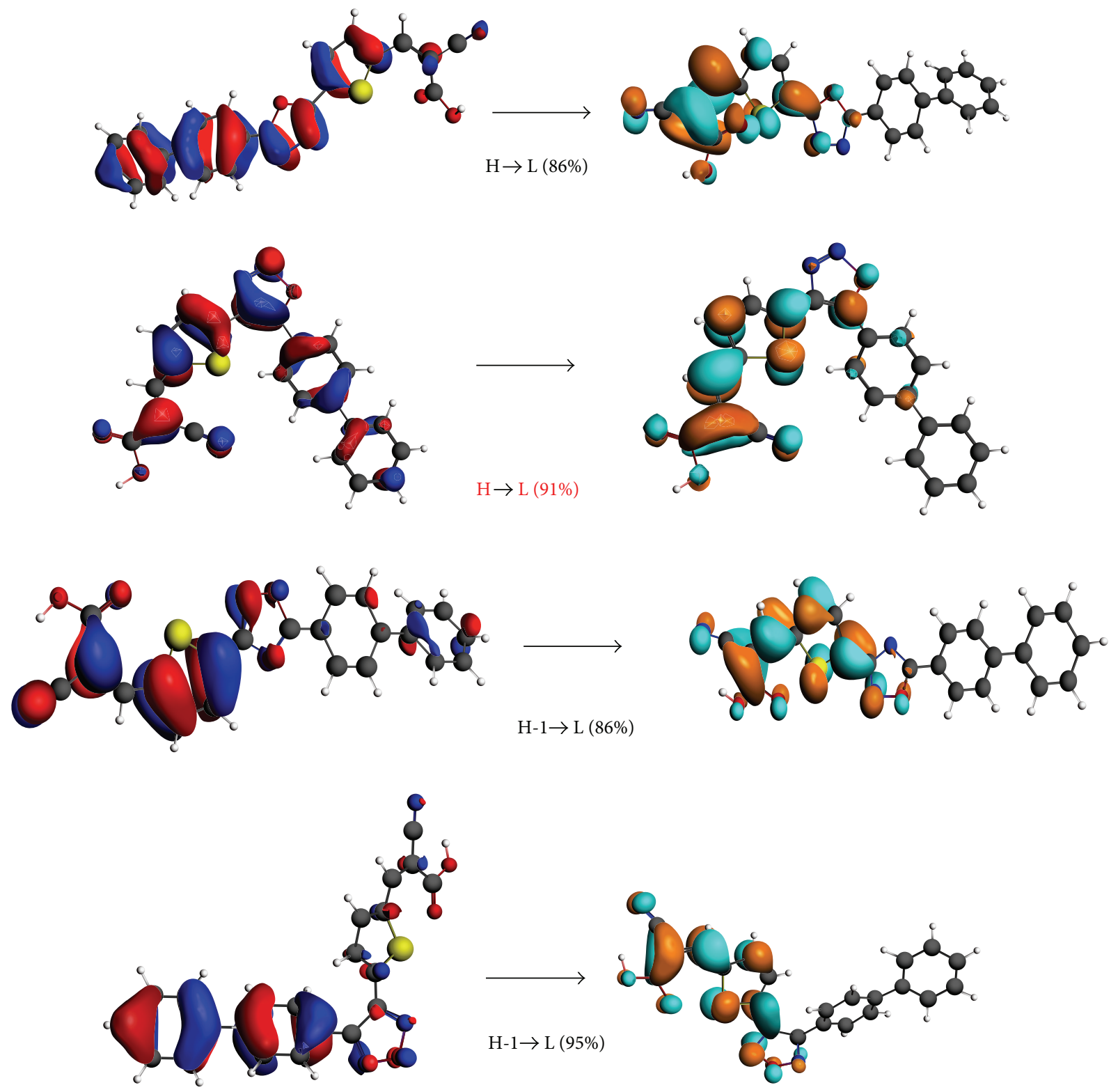

FIGURE 3: Major transition of systems 1-4.

electron injection. The $\Delta G^{\text {inject }}$ of systems 1-4 increases in the order of system $2(0.692)>$ system $1(0.618)>$ system $3(0.335)>$ system $4(0.281)$. Therefore, the order of driving force of the systems will be system $2>$ system $1>$ system $3>$ system 4 . There is only slight difference of LHE for systems 1-4. It demonstrates that all the photosensitizers will give comparable photocurrents. These results indicate that system 2 can be considered as plausible due to more positive $\Delta G^{\text {inject }}(0.632 \mathrm{eV})$ and larger LHE value (0.74), which results in higher IPCE. 


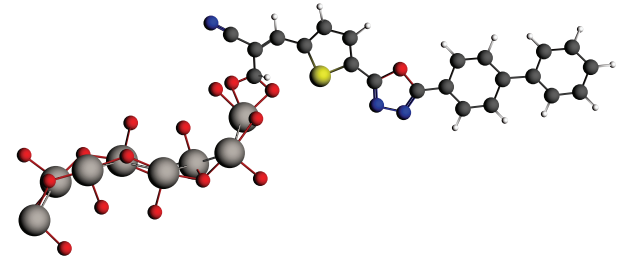

Dye- $1 /\left(\mathrm{TiO}_{2}\right)_{8}$

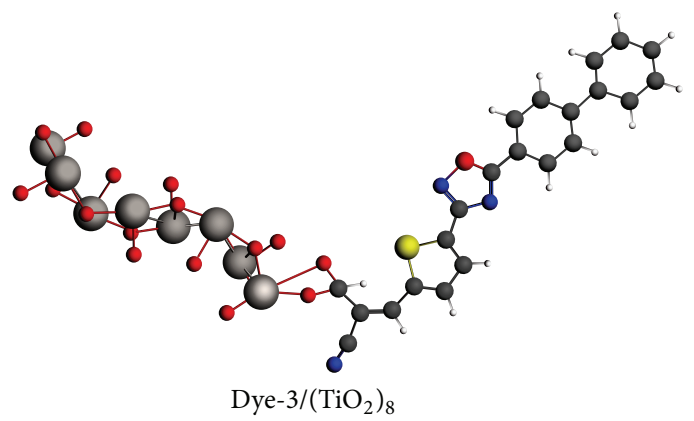

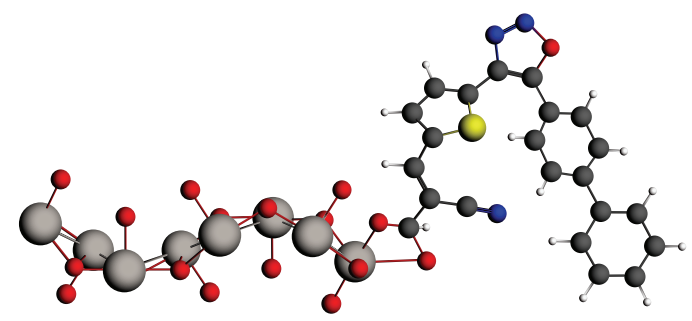

Dye- $2 /\left(\mathrm{TiO}_{2}\right)_{8}$

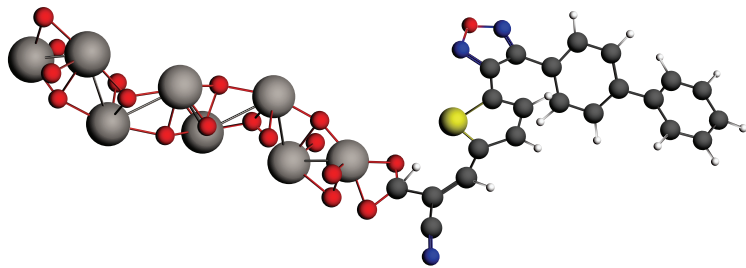

Dye- $4 /\left(\mathrm{TiO}_{2}\right)_{8}$

Figure 4: The model of systems $1-4$ with $\left(\mathrm{TiO}_{2}\right)_{8}$.

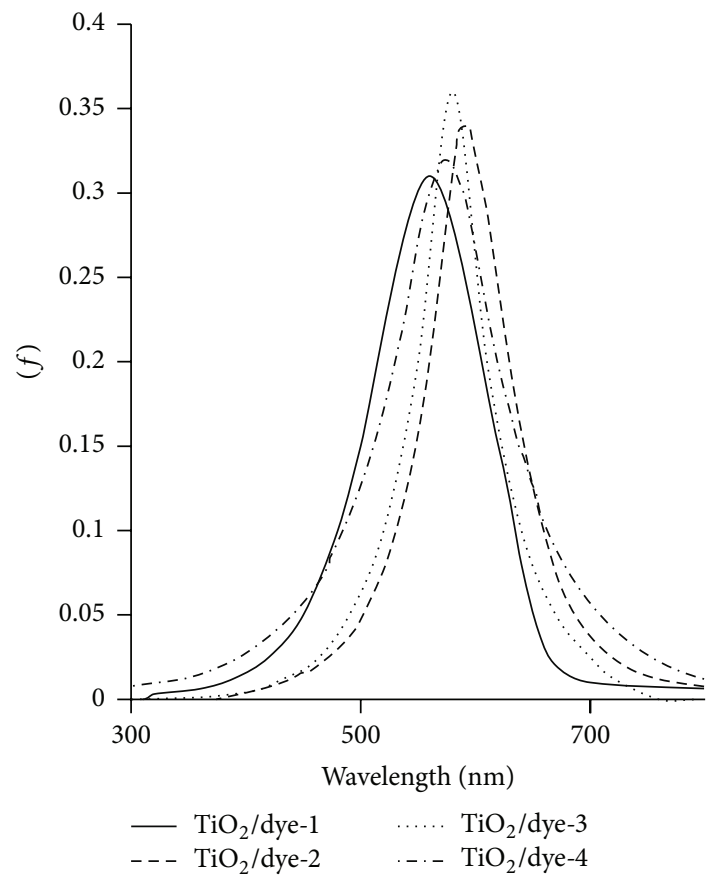

FIGURE 5: Simulated absorption spectra of $\left(\mathrm{TiO}_{2}\right)_{8} /$ systems 1-4.

\section{Conclusion}

Four photosensitizers based on oxadiazole isomers as piconjugated spacer were designed and simulated using DFT/TD-DFT. The UV-Vis spectroscopic properties as well as the driving force $\left(\Delta G^{\text {inject }}\right)$ of systems $1-4$ show that these dyes are potential to be a good photosensitizer in DSSC. The results show that LUMO of the dyes is greater than
TABLE 3: Lowest absorption energy $\Delta E$, maximum absorption $\lambda_{\max }$, and oscillating strength $(f)$.

\begin{tabular}{lccc}
\hline System & $\lambda_{\max }(\mathrm{nm})$ & $\Delta E(\mathrm{eV})$ & $f$ \\
\hline 1 & 560 & 2.217 & 0.31 \\
2 & 690 & 2.104 & 0.34 \\
3 & 576 & 2.140 & 0.36 \\
4 & 582 & 2.159 & 0.30 \\
\hline
\end{tabular}

TABLE 4: Free energy of electron injection $\Delta G^{\text {inject }}(\mathrm{eV})$ and light harvesting efficiency (LHE).

\begin{tabular}{lcc}
\hline System & $\Delta G^{\text {inject }}$ & LHE \\
\hline 1 & 0.613 & 0.738 \\
2 & 0.692 & 0.740 \\
3 & 0.335 & 0.801 \\
4 & 0.281 & 0.796 \\
\hline
\end{tabular}

the conduction band of $\mathrm{TiO}_{2}$ indicating that these dyes are thermodynamically favorable in charge transfer into the conduction band of $\mathrm{TiO}_{2}$. Similarly, from system 1 to system 4 , the absorption spectra are red-shifted due to the increased delocalization of the $\pi^{*}$ orbital of the conjugated framework caused by the interaction between the carboxylate group and the $\mathrm{Ti}^{+4}$ ions that directly decreases the energy of the $\pi^{*}$ level. Moreover, there is no distinct difference in the LHE of systems $1-4$. Therefore, it can be concluded that system 2 with 1,2,3-oxadiazole shows a balance among the different crucial parameters and is expected to be a promising sensitizer in the DSSC field. 


\section{Conflict of Interests}

The authors declare that there is no conflict of interests regarding the publication of this paper.

\section{Acknowledgments}

The authors would like to acknowledge the support provided by King Abdulaziz City for Science and Technology (KACST) through the Science \& Technology Unit at King Fahd University of Petroleum \& Minerals (KFUPM) for funding this work through Project no. 11-ENE1635-04 as part of the National Science, Technology and Innovation Plan. KFUPM is also acknowledged for supporting this research. The authors would like to acknowledge the Center of Research Excellence for Renewable Energy at KFUPM. Mr. Umer Mehmood would like to thank Mr. Muhammad Daud for his help.

\section{References}

[1] U. Mehmood, S.-U. Rahman, K. Harrabi, I. A. Hussein, and B. V. S. Reddy, "Recent advances in dye sensitized solar cells," Advances in Materials Science and Engineering, vol. 2014, Article ID 974782, 12 pages, 2014.

[2] E.-S. Ha, B. Yoo, H. Baik, Y. Lee, and K.-J. Kim, "Photocurrent enhancement of dye-sensitized solar cells owing to increased dye-adsorption onto silicon-nanoparticle-coated titanium-dioxide films," Chemistry-An Asian Journal, vol. 7, no. 7, pp. 1624-1629, 2012.

[3] X. Lu, G. Zhou, H. Wang, Q. Feng, and Z.-S. Wang, "Near infrared thieno[3,4-b]pyrazine sensitizers for efficient quasisolid-state dye-sensitized solar cells," Physical Chemistry Chemical Physics, vol. 14, no. 14, pp. 4802-4809, 2012.

[4] S. Agrawal, N. J. English, K. R. Thampi, and J. M. D. MacElroy, "Perspectives on ab initio molecular simulation of excited-state properties of organic dye molecules in dye-sensitised solar cells," Physical Chemistry Chemical Physics, vol. 14, no. 35, pp. 12044-12056, 2012.

[5] U. Mehmood, I. A. Hussein, K. Harrabi, M. Mekki, S. Ahmed, and N. Tabet, "Hybrid $\mathrm{TiO}_{2}-$ multiwall carbon nanotube (MWCNTs) photoanodes for efficient dye sensitized solar cells (DSSCs)," Solar Energy Materials and Solar Cells, vol. 140, pp. 174-179, 2015.

[6] U. Mehmood, S. Ahmed, I. A. Hussein, and K. Harrabi, "Cosensitization of $\mathrm{TiO}_{2}-\mathrm{MWCNTs}$ hybrid anode for efficient dyesensitized solar cells," Electrochimica Acta, vol. 173, pp. 607-612, 2015.

[7] Z. Tian, M. Huang, B. Zhao et al., "Low-cost dyes based on methylthiophene for high-performance dye-sensitized solar cells," Dyes and Pigments, vol. 87, no. 3, pp. 181-187, 2010.

[8] M. K. Panda, K. Ladomenou, and A. G. Coutsolelos, "Porphyrins in bio-inspired transformations: light-harvesting to solar cell," Coordination Chemistry Reviews, vol. 256, no. 21-22, pp. 2601-2627, 2012.

[9] C. Hosokawa, H. Higashi, H. Nakamura, and T. Kusumoto, "Highly efficient blue electroluminescence from a distyrylarylene emitting layer with a new dopant," Applied Physics Letters, vol. 67, p. 3853, 1995.

[10] J. Jacob, S. Sax, T. Piok, E. J. W. List, A. C. Grimsdale, and K. Múllen, "Ladder-type pentaphenylenes and their polymers: efficient blue-light emitters and electron-accepting materials via a commmon intermediate," Journal of the American Chemical Society, vol. 126, no. 22, pp. 6987-6995, 2004.

[11] S. Anderson, P. N. Taylor, and G. L. B. Verschoor, "Benzofuran trimers for organic electroluminescence," Chemistry-A European Journal, vol. 10, no. 2, pp. 518-527, 2004.

[12] S.-H. Jin, M.-Y. Kim, J. Y. Kim, K. Lee, and Y.-S. Gal, "Highefficiency poly(p-phenylenevinylene)-based copolymers containing an oxadiazole pendant group for light-emitting diodes," Journal of the American Chemical Society, vol. 126, pp. 24742480, 2004.

[13] C. Wang, G.-Y. Jung, Y. Hua et al., "An efficient pyridine- and oxadiazole-containing hole-blocking material for organic lightemitting diodes: synthesis, crystal structure, and device performance," Chemistry of Materials, vol. 13, no. 4, pp. 1167-1173, 2001.

[14] S. I. Panchamukhi, N. Belavagi, M. H. Rabinal, and I. A. Khazi, "Synthesis and optoelectronic properties of symmetrical thiophene based 2,5-disubstiuted 1,3,4-oxadiazoles: highly fluorescent materials for OLED applications," Journal of Fluorescence, vol. 21, no. 4, pp. 1515-1519, 2011.

[15] W. Zhu, R. Yao, and H. Tian, "Synthesis of novel electrotransporting emitting compounds," Dyes and Pigments, vol. 54, no. 2, pp. 147-154, 2002.

[16] X. Zhan, Y. Liu, X. Wu, S. Wang, and D. Zhu, "New series of blue-emitting and electron-transporting copolymers based on fluorene," Macromolecules, vol. 35, no. 7, pp. 2529-2537, 2002.

[17] S.-J. Chung, K.-Y. Kwon, S.-W. Lee et al., "Highly efficient lightemitting diodes based on an organic-soluble poly( $p$-phenylenevinylene) derivative carrying the electron-transporting PBD moiety," Advanced Materials, vol. 10, pp. 1112-1116, 1998.

[18] W. G. Skene and S. A. Pérez Guarìn, "Spectral characterization of thiophene acylhydrazides," Journal of Fluorescence, vol. 17, no. 5, pp. 540-546, 2007.

[19] G. Te Velde, F. M. Bickelhaupt, E. J. Baerends et al., "Chemistry with ADF," Journal of Computational Chemistry, vol. 22, no. 9, pp. 931-967, 2001.

[20] J. Wang, H. Li, N.-N. Ma, L.-K. Yan, and Z.-M. Su, “Theoretical studies on organoimido-substituted hexamolybdates dyes for dye-sensitized solar cells (DSSC)," Dyes and Pigments, vol. 99, no. 2, pp. 440-446, 2013.

[21] W. Fan, D. Tan, and W.-Q. Deng, "Acene-modified triphenylamine dyes for dye-sensitized solar cells: a computational study," ChemPhysChem, vol. 13, no. 8, pp. 2051-2060, 2012.

[22] W. Sang-Aroon, S. Saekow, and V. Amornkitbamrung, "Density functional theory study on the electronic structure of Monascus dyes as photosensitizer for dye-sensitized solar cells," Journal of Photochemistry and Photobiology A: Chemistry, vol. 236, pp. 3540, 2012.

[23] X. Zarate, E. Schott, T. Gomez, and R. Arratia-Pérez, “Theoretical study of sensitizer candidates for dye-sensitized solar cells: peripheral substituted dizinc pyrazinoporphyrazinephthalocyanine complexes," The Journal of Physical Chemistry A, vol. 117, pp. 430-438, 2013.

[24] J. Zhang, Y.-H. Kan, H.-B. Li, Y. Geng, Y. Wu, and Z.-M. Su, "How to design proper $\pi$-spacer order of the D- $\pi$-A dyes for DSSCs? A density functional response," Dyes and Pigments, vol. 95, no. 2, pp. 313-321, 2012.

[25] D. Rocca, R. Gebauer, F. de Angelis, M. K. Nazeeruddin, and S. Baroni, "Time-dependent density functional theory study of squaraine dye-sensitized solar cells," Chemical Physics Letters, vol. 475, no. 1-3, pp. 49-53, 2009. 
[26] W. Fan, "Incorporation of thiadiazole derivatives as $\pi$-spacer to construct efficient metal-free organic dye sensitizers for dyesensitized solar cells: a theoretical study," Communications in Computational Chemistry, vol. 1, pp. 152-170, 2013.

[27] U. Mehmood, I. A. Hussein, K. Harrabi, and B. V. S. Reddy, "Density functional theory study on dye-sensitized solar cells using oxadiazole-based dyes," Journal of Photonics for Energy, vol. 5, no. 1, Article ID 053097, 2015.

[28] U. Mehmood, I. A. Hussein, M. Daud, S. Ahmed, and K. Harrabi, "Theoretical study of benzene/thiophene based photosensitizers for dye sensitized solar cells (DSSCs)," Dyes and Pigments, vol. 118, pp. 152-158, 2015.

[29] A. Anthonysamy, Y. Lee, B. Karunagaran et al., "Molecular design and synthesis of ruthenium(II) sensitizers for highly efficient dye-sensitized solar cells," Journal of Materials Chemistry, vol. 21, no. 33, pp. 12389-12397, 2011. 

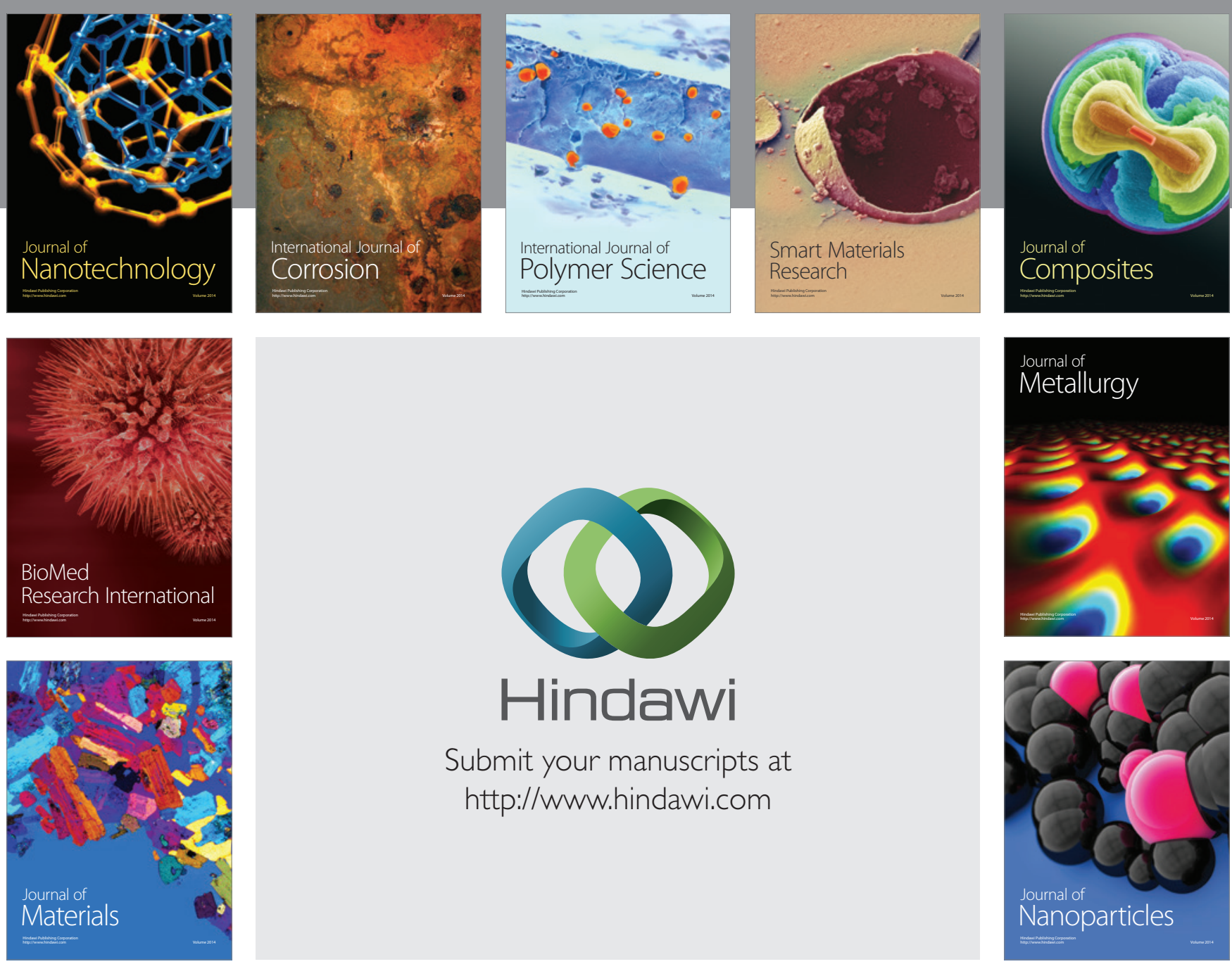

Submit your manuscripts at http://www.hindawi.com
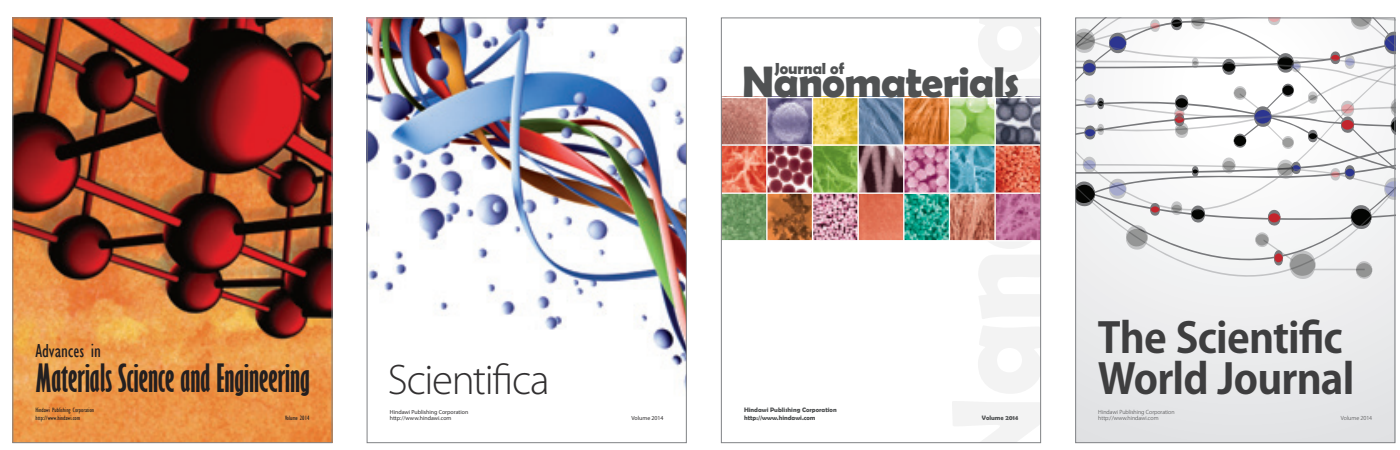

\section{The Scientific World Journal}
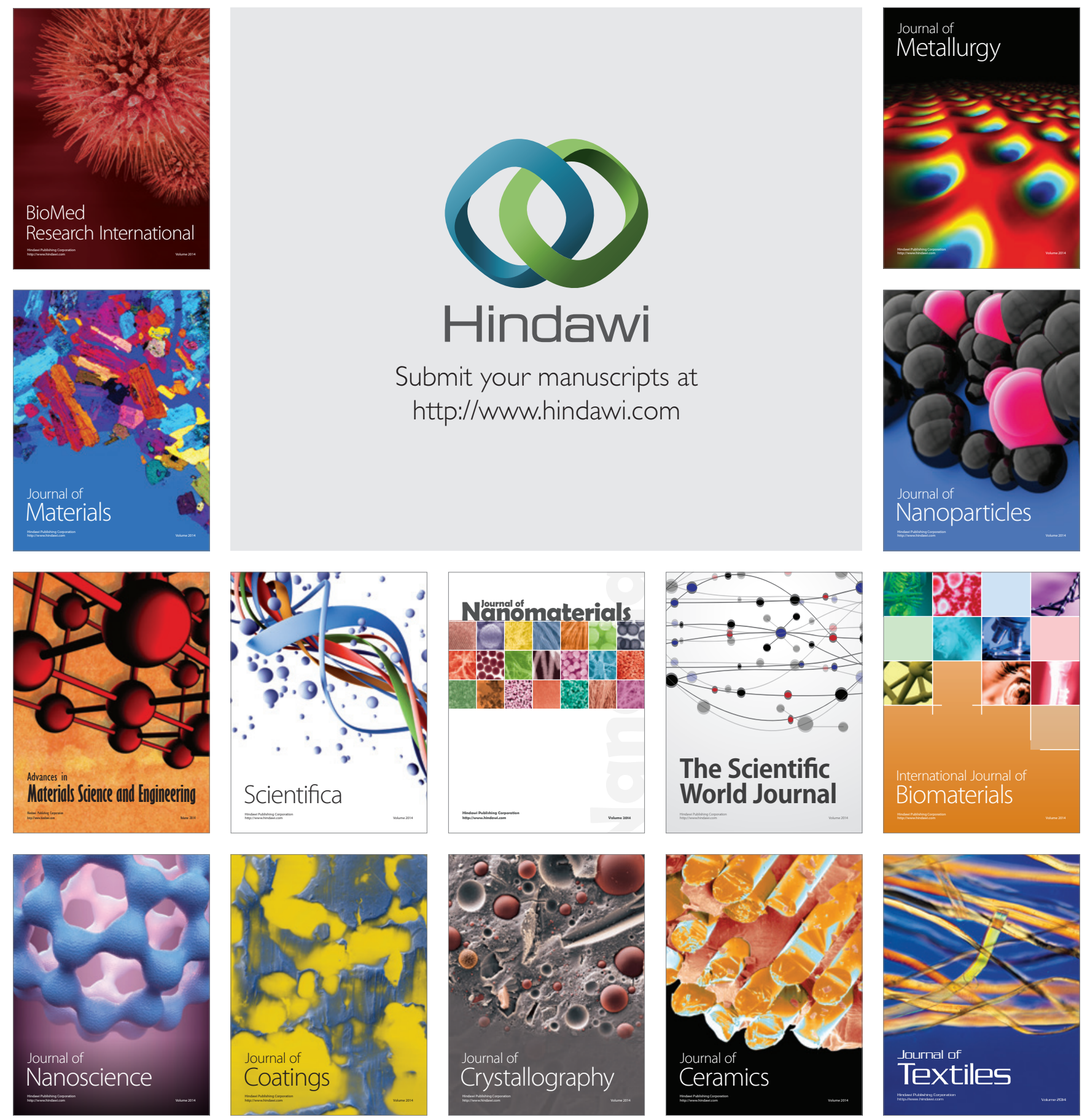